5 Fabrizi GM, Cavallaro T, Angiari C, et al. Giant axon and neurofilament accumulation in Charcot-Marie-Tooth disease type 2E. Neurology 2004:62:1429-31.

6 Azzedine H, Ravise N, Verny C, et al. Spine deformities in Charcot-Marie-Tooth 4C caused by SH3TC2 gene mutations. Neurology 2006;67:602-6.

7 Bomont $\mathrm{P}$, Cavalier $\mathrm{L}$, Blondeau $\mathrm{F}$, et al. The gene encoding gigaxonin, a new member of the cytoskeletal BTB/kelch repeat family, is mutated in giant axonal neuropathy. Nat Genet 2000;26:370-4.

8 Cavalier L, BenHamida C, Amouri R, et al. Giant axonal neuropathy locus refinement to a $<590 \mathrm{~kb}$ critical interval. Eur J Hum Genet 2000;8:527-34.

9 Kuhlenbaumer G, Young P, Oberwittler C, et al. Giant axonal neuropathy (GAN): case report and two novel mutations in the gigaxonin gene. Neurology 2002:58: 1273-6.
10 Bomont $\mathbf{P}$, loos $\mathrm{C}$, Yalcinkaya $\mathrm{C}$, et al. Identification of seven novel mutations in the GAN gene. Hum Mutat 2003;21:446.

11 Brockmann K, Pouwels PJ, Dechent $P$, et al. Cerebral proton magnetic resonance spectroscopy of a patient with giant axonal neuropathy. Brain Dev 2003;25:45-50.

12 Bruno C, Bertini E, Federico A, et al. Clinical and molecular findings in patients with giant axonal neuropathy (GAN). Neurology 2004;62:13-16.

13 Demir E, Bomont P, Erdem S, et al. Giant axonal neuropathy: clinical and genetic study in six cases. J Neurol Neurosurg Psychiatry 2005;76:825-32.

14 Pena DJ. Giant axonal neuropathy: An inborn error of organization of intermediate filaments. Muscle Nerve 1982;5:166-72.

15 Ding J, Allen E, Wang W, et al. Gene targeting of GAN in mouse causes a toxic accumulation of microtubule-associated protein 8 and impaired retrograde axonal transport. Hum Mol Genet 2006;15:1451-63.

\title{
NEUROLOGICAL PICTURE
}

\section{The sonographic piffall of carotid collateralisation via the vasa vasorum}

A

52-year-old man with obesity, type 2 diabetes mellitus and hypertension was admitted because of sudden onset of left hemiparesis and somnolence. Brain MRI disclosed a recent right thalamic stroke and multiple encephaloclastic lesions, suggestive of vascular sequelae. Carotid ultrasound demonstrated occlusion of the right internal carotid artery (ICA) and residual flow in the periphery of the left ICA lumen (fig 1A, B). Subocclusive stenosis was suspected. Carotid arteriography confirmed atherosclerotic occlusion of both bulbar ICAs. On the left side, however, filiform collateralisation with a spiral configuration was seen, extending from the ICA bulb to the cavernous segment (fig $1 \mathrm{C}$ ). The patient was offered medical treatment.

Collateralisation through the vasa vasorum of an atheromatous occlusion of the ICA is a rare finding. Growth of collaterals in the wall of the vessel is a slow process, stimulated by the proangiogenic properties of the plaque.

Differentiating carotid occlusion with collateralisation from pre-occlusive stenosis is of the utmost importance because there is no benefit of endarterectomy or angioplasty in the first situation.

Carotid ultrasound is a reliable method in the assessment of ICA stenosis and occlusion. However, the findings of residual flow with normal velocities and waveform may erroneously be attributed to subocclusive carotid disease $^{2}$ in which it has been shown that velocity measurements start to decrease. Therefore, corroboration with arteriography is recommended. High resolution transverse colour coded sections showing segments of flow within the ICA wall itself, outlining the circumference of the vessel may be a clue to the correct diagnosis.

\section{João P Soares-Fernandes, Manuel Ribeiro,} Zita Magalhães, Jaime F Rocha Department of Neuroradiology, Hospital de S Marcos, Braga, Portugal

Correspondence to: Dr João Paulo SoaresFernandes, Serviço de Neurorradiologia, Hospital de S Marcos, Largo Engenheiro Carlos Amarante, Apartado 2242, 4701-965 Braga, Portugal; jsł@bragatel.pt
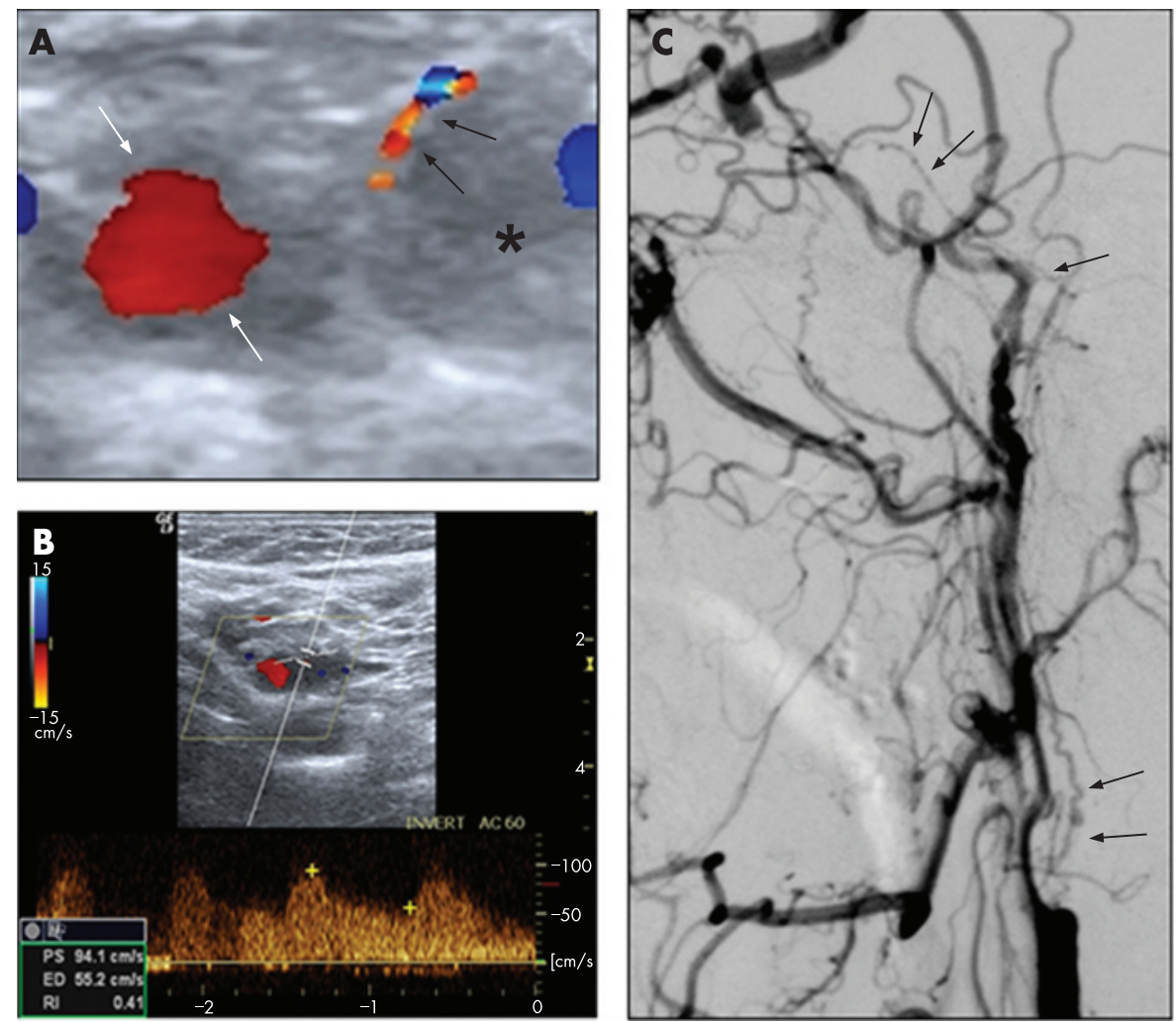

Figure 1 (A) Colour coded duplex ultrasonography, transverse section, $1 \mathrm{~cm}$ above the carotid bifurcation, shows the occluded internal carotid artery (ICA) lumen $\left(^{*}\right)$ and a thin segment of flow within its wall (black arrows), outlining the perimeter of the artery. External carotid artery is normal (white arrows). (B) Spectral tracing from the same segment as in (A), reveals a normal waveform and velocity. (C) Contrast arteriogram of the left ICA, arterial phase, lateral view, demonstrates a rounded proximal stump. Spiral vasa vasorum (black arrows) originate from the bulb and contribute to the filling of the cavernous segment. The true lumen of the ICA is never filled.

Competing interests: None

\section{REFERENCES}

1 Bo WJ, Mercuri M, Tucker R, et al. The human carotid atherosclerotic plaque stimulates angiogenesis on the chick chorioallantoic membrane. Atherosclerosis 1992:94:71-8.

2 Kriegshauser JS, Patel MD, Nelson KD, et al. Carotid pseudostring sign from vasa vasorum collaterals. $J$ Ultrasound Med 2003;22:959-63. 